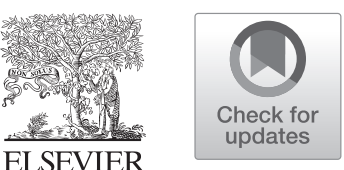

\title{
Diagnostic Value of Presepsin for Bacterial Infection in Cirrhosis: A Pilot Study
}

\author{
Simone Novelli ${ }^{\mathrm{a}, \star}$, Vincenzo Morabito ${ }^{\mathrm{b}}$, Franco Ruberto ${ }^{\mathrm{b}}$, Fabiano Bini ${ }^{\mathrm{b}}$, Franco Marinozzi $^{\mathrm{b}}$, \\ Francesco Pugliese ${ }^{\mathrm{b}}$, Pasquale Berloco ${ }^{\mathrm{b}}$, and Renzo Pretagostini ${ }^{\mathrm{b}}$

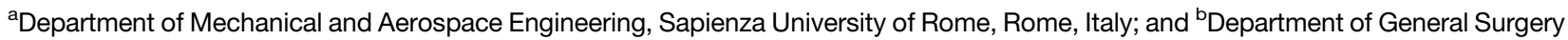 \\ and Organ Transplantation, Sapienza University of Rome, Rome, Italy
}

\begin{abstract}
Introduction. Presepsin (or sCD14) has been identified as a protein whose levels increase specifically in the blood of patients with bacterial infections. In this study, we evaluated the clinical performance of sCD14 and its usefulness in the early diagnosis of bacterial infection in decompensated cirrhotic patients.

Materials. Seventy patients were enrolled in this study. The mean age of patients was 49.5 years, and 21 were women and 49 men. The heparinized whole blood for the PATHFAST test was used in the evaluation of bacterial infection (T0). The test was repeated after 48 hours (T1); at 96 hours (T2); at 144 hours (T3); then at 15 days (T4) to monitor the clinical responses to therapeutic interventions.

Results. Forty-nine patients tested positive for sCD14. The mean sCD14 level was $1854 \pm$ $1744 \mathrm{pg} / \mathrm{mL}$. Microbiological findings confirmed the presence of bacterial infections within $84 \pm 4.8 \mathrm{~h}$ from enrollment in all 49 positive patients. Thirty-eight patients were considered responders to empirical antibiotic therapy with a decrease of presepsin at the different time points, while an increased level of sCD14 was highlighted in 11 patients. When the test was performed, $45 \%$ of the patients showed no signs or symptoms of bacterial infection. At 30 days of follow-up 43 patients survived, and 6 patients died from septic shock.

Conclusions. The PATHFAST test highlighted the presence of infection in a very short time (15 minutes), and the presepsin could be considered an early biomarker in patients with cirrhosis. A greater number of patients are necessary to confirm these data.
\end{abstract}

T HE natural course of chronic liver disease is often complicated by acute episodes of potentially reversible decompensation, triggered by a precipitating event such as a bacterial infection. A bacterial infection may be present at admission, or it may appear during the hospital stay in $30 \%$ to $60 \%$ of hospitalized patients $[1,2]$.

Several factors are known to facilitate a bacterial infection: hepatic disease stage, malnutrition, impairment of the cutaneo-mucous barrier, associated pathology, upper gastrointestinal hemorrhage, and invasive maneuvers $[3,4]$. Infection induces a systemic host response with 3 stages of severity called sepsis, severe sepsis (when an acute organ failure occurs), and septic shock (when hypotension does not respond to adequate fluid resuscitation) with a mortality rate reaching up to $78 \%$ [5-9].

(c) 2020 The Authors. Published by Elsevier Inc. This is an open access article under the CC BY-NC-ND license (http://

creativecommons.org/licenses/by-nc-nd/4.0/).

230 Park Avenue, New York, NY 10169
Epidemiology and Pathogenesis of Bacterial Infections

Spontaneous bacterial peritonitis (SBP) and urinary infections are the most frequent infections represented in cirrhotic patients. Immune defects, mainly acquired but also genetic, and bacterial translocation are the principal mechanism involved in the pathogenesis of infection in cirrhosis [10]. In addition, bacterial translocation from the gut is a well-known source of life-threatening infection, and the most frequent causative

Simone Novelli and Vincenzo Morbito contributed equally to this work.

${ }^{*}$ Address correspondence to Simone Novelli, PhD, Sapienza University, Via Eudossiana 18, 00100 Roma, Italy. E-mail: Simone.novelli@uniroma1.it

$0041-1345 / 20$

https://doi.org/10.1016/j.transproceed.2020.02.042 
organisms in community-acquired infections are Gramnegative bacilli, mainly Escherichia coli (60\%).

Liver dysfunction is associated with an impaired immune defense against bacteria, which worsens over time and with disease progression. Both humoral and cell-mediated immunity are depressed.

The innate immune system serves as a first-line defense mechanism against bacteria and toxins. The main effector cells of the innate immune system are phagocytic cells, such as macrophages, neutrophils, and monocytes. The main cellular components of the innate immune system within the liver are the Kupffer cells. The liver is extremely important in innate immunity since Kupffer cells represent $80 \%$ to $90 \%$ of the tissue macrophages in the human body. In the presence of cirrhosis, the mechanisms of innate immune dysfunction are numerous. First, Kupffer cells are bypassed through multiple intra- and extrahepatic shunts. Second, decreased liver protein synthesis generates defects in complement production. Third, in cirrhosis, there is evidence for a dysfunctional and hyporesponsive state of the innate immune system, a phenomenon that is known as immune paralysis.

Beside this immunodeficient state, in the early phase of bacterial sepsis, circulating levels of the proinflammatory cytokines such as tumor necrosis factor alpha and interleukin (IL)-6 are significantly higher in infected patients with cirrhosis than in those without [11]. This excessive proinflammatory response is recapitulated ex vivo with the stimulation of isolated peripheral blood mononuclear cells or monocytes from patients with cirrhosis by lipopolysaccharides (LPS), which are a part of the external membrane of Gram-negative bacteria [12]. This bacteria-induced "cytokine storm" contributes to sepsis-related organ failure.

\section{Diagnosis}

Early diagnosis and treatment of infection is pivotal in the management of patients with decompensated cirrhosis. Blood culture is frequently used as the gold standard diagnostic method for sepsis.

However, it usually takes 3 to 7 days to obtain the results, and the culture frequently yields low positive results. Therefore, the general practical medical treatment used for sepsis is based on the doctor's own experience (empirical therapy).

Furthermore, bacterial infections in patients with cirrhosis can be asymptomatic or pauci-symptomatic and have to be taken into consideration in any cirrhotic patient with a sudden impairment of liver function [13]. The prognosis of these patients is mainly dependent on a prompt and accurate diagnosis [14].

For these reasons, the use of systemic inflammatory response syndrome (SIRS) or early biomarkers for diagnosis are used in cirrhotic patients. The application of SIRS is particularly difficult due to the following findings [15-18]: reduced baseline polymorphonuclear cell count due to hypersplenism; elevated baseline heart rate due to hyperdynamic circulatory syndrome; hyperventilation due to hepatic encephalopathy; and blunted elevation of body temperature that is often observed in cirrhotic patients. SIRS is present in $10 \%$ and $30 \%$ of decompensated cirrhotic patients without infection and in $57 \%$ to $70 \%$ of infected patients, which suggests that SIRS is not the best marker of infection in the cirrhotic population.

Concentrations of C-reactive protein (CRP) and procalcitonin (PCT) have been suggested as early markers of infection. While CRP is produced predominantly by hepatocytes, PCT is produced ubiquitously by thyroidal and extrathyroidal tissues, including the liver [19]. These 2 acute-phase serum proteins are commonly used as early markers of infection in the noncirrhotic population with a significant sensibility [20]. On the other hand, patients with liver failure could present an attenuated production of acute-phase proteins, especially CRP, in response to infection.

In fact, conflicting results exist regarding threshold values and diagnostic accuracy of CRP and PCT in patients with cirrhosis. Bota et al [21], in the evaluation on 79 cirrhotic patients, showed that the serum CRP concentration (admission $11.2 \pm 4.6$ vs $13.0 \pm 5.8$, maximum $13.9 \pm 6.4$ vs $18.8 \pm 7.3 \mathrm{mg} / \mathrm{dL}$ ) and PCT (admission $1.3 \pm 0.9$ vs $2.0 \pm$ 1.4 , maximum $3.3 \pm 1.8$ vs $3.4 \pm 2.1 \mathrm{ng} / \mathrm{mL}$ ) were slightly lower in infected patients with cirrhosis than in infected patients without cirrhosis, but the differences were not statistically significant.

Recently, a new biomarker was introduced. Presepsin, which is approximately $13 \mathrm{kDa}$, has been identified as a protein whose levels increase specifically in the blood of sepsis patients. Presepsin is thought to be a fragment of CD14, the lipopolysaccharide-binding protein (LPS-LBP) complex receptor, and it is produced in response to bacterial infections.

CD14 also exists in a soluble form (sCD14), a glycoprotein that derives from either the protease-mediated membrane CD14 shedding [22,23] or liver synthesis as a type II acute phase reactant [24]. LBP is a $58-\mathrm{kDa}$ glycoprotein synthesized in the liver that is released into circulation as a type I acute-phase reactant [25-27]. Levels of LBP peak in serum shortly after bacteremia or endotoxemia. Once in the circulation, LBP forms a complex with LPS that enhances the binding of LPS with CD14 receptors [28]. Membrane CD14 is associated with TLR-4, which transduces a signal from the CD14-bound LPS to the cell nucleus, triggering a cascade of inflammatory cytokines [29]. Some of these cytokines, specifically IL-1 and IL-6, induce the synthesis of acute-phase proteins in the liver [30]. Membrane CD14, sCD14, and LBP thus participate in a complex mechanism of immune regulation involving both up regulation and down regulation of the inflammatory process triggered by LPS.

In a study of 207 patients, Endo et al [31] conducted the clinical usefulness of presepsin for discriminating between 
bacterial and nonbacterial infections (including systemic inflammatory response syndrome) by comparing it with PCT and IL-6. The results showed a higher sensibility and specificity of CD14s than PCT and IL-6 in asserting the presence of bacterial infection.

Additionally, the measurement of presepsin concentrations is useful for evaluating the severity of infection and also for monitoring the clinical responses to therapeutic interventions [32].

\section{Aim of Study}

The first endpoint of the study was the evaluation of the clinical performance of presepsin and its usefulness in the early diagnosis of bacterial infections in cirrhotic patients. The second endpoint was based on an evaluation of antibiotic therapy response compared to presepsin levels. Finally, the outcome of patients at 30 days was evaluated.

\section{MATERIALS AND METHODS}

The study was compliant with the 1975 Declaration of Helsinki as revised in 2008 and approved by the Ethical Committee of Umberto I Policlinic of Rome, Italy (ref. no. 3101). Written informed consent was obtained for all participants.

\section{Patients}

Seventy decompensated cirrhotic patients hospitalized at our University Hospital were enrolled (Table 1). Diagnosis of cirrhosis was based on liver biopsy, when available, or on obvious clinical, biochemical, or ultrasonographic and endoscopic features. Seven other patients with a diagnosis of hepatic carcinoma were excluded.

At admission, previous relevant clinical data, such as origin of liver disease, history of alcohol abuse, ascites, encephalopathy, gastrointestinal bleeding, acute or chronic renal failure, and coexistence of other diseases, were recorded.

The main cause of hospitalization was identified, and basal clinical and biochemical parameters were assessed to define the severity of liver disease and renal function. Mean arterial pressure, heart rate, respiratory rate, and body temperature were measured, and the presence of systemic inflammatory response syndrome (SIRS) was investigated [17]. The severity of liver disease was assessed using the Model for End-Stage Liver Disease (MELD) score [33]. Renal failure was diagnosed according to international criteria [34]. Complications of cirrhosis were treated according to recent guidelines [35].

\section{Diagnosis of Infection: Evaluation of Presepsin}

The heparinized whole blood for the PATHFAST Assay System (PAS) was used in the evaluation of bacterial infection presence at admission (T0). The test was repeated after 48 hours (T1); at 96 hours (T2); at 144 hours (T3), then at 15 days (T4) to monitor the clinical responses to therapeutic interventions.

At the same time points, blood and urine cultures and ascetic fluid cell analysis were performed. In accordance to local epidemiology, empirical antibiotic therapy (EAT) with beta-lactamase was administered at (T0) in patients who tested positive for presepsin
Table 1. Demographic, Clinical, and Biochemical Characteristics of Patients With Decompensated Cirrhosis at Admission

\begin{tabular}{lc}
\hline Patients (No. 70) & \\
Age (years) & $49.5 \pm 7.6$ \\
Sex (male/female) & $49 / 21$ \\
MELD Score & $23 \pm 3.6$ \\
Serum bilirubin $(\mathrm{mg} / \mathrm{dL})$ & $11 \pm 2.1$ \\
Serum creatinine $(\mathrm{mg} / \mathrm{dL})$ & $1.6 \pm 1.7$ \\
Serum albumin $(\mathrm{g} / \mathrm{dL})$ & $2.4 \pm 0.9$ \\
Serum lactate $(\mathrm{mmol} / \mathrm{L})$ & $2.1 \pm 0.7$ \\
Arterial ammonia $(\mathrm{mg} / \mathrm{dL})$ & $114 \pm 46.3$ \\
PMN count $\left(\mathrm{cell} / \mathrm{mm}^{3}\right)$ & $9789 \pm 4122$ \\
INR & $2.1 \pm 1.05$ \\
mAP (mm Hg) & $77 \pm 8.9$ \\
HR (b/min) & $91 \pm 3.5$ \\
Cause of Cirrhosis & \\
Alcohol & $20(28 \%)$ \\
HCV & $29(42 \%)$ \\
HBV & $14(20 \%)$ \\
PBC & $7(10 \%)$ \\
Precipitating Events & \\
Ascites & $21(30 \%)$ \\
Variceal bleeding & $18(26 \%)$ \\
Renal failure & $15(21 \%)$ \\
Suspected bacterial infection & $8(11.5 \%)$ \\
Encephalopathy & $8(11.5 \%)$ \\
\hline
\end{tabular}

Categorical data were summarized as proportions and percentages; continuous data, as mean values and standard deviations, were reported.

Abbreviations: HBV, hepatitis $B$ virus related; $\mathrm{HCV}$, hepatitis $\mathrm{C}$ virus related; $\mathrm{HR}$, heart rate; INR, international normal ratio; mAP, mean arterial pressure; MELD, Model for End-Stage Liver Disease; PMN, polymorph-nuclear; PBC, primary biliary cirrhosis.

\section{PATHFAST Assay System}

The PAS contains magnetic particles coated with mouse monoclonal antibodies and alkaline phosphatase (ALP)-labeled rabbit polyclonal antibodies. Presepsin in the specimen binds to the antipresepsin antibodies to form an immunocomplex with the ALP-labeled antibodies and the antibody-coated magnetic particles. After removal of the unbound ALP-labeled antibodies, a chemiluminescent substrate was added to the immunocomplex. After a short incubation period, the luminescence generated by the enzyme reaction was detected to calculate the concentration of presepsin in the samples. The assay time was 15 minutes using a sample volume of $100 \mu \mathrm{L}$. The entire procedure was automatically performed on the PATHFAST analyzer. Heparinized whole blood samples were collected from 25 patients at admission and immediately assayed with the PATHFAST assay. A value $>377 \mathrm{pg} / \mathrm{mL}$ was considered positive.

\section{Definitions}

Patients were considered to have SIRS when they fulfilled the criteria established by the most recent international guidelines. Sepsis was diagnosed in the presence of SIRS and a known or highly suspected infection. Septic shock was defined as sepsis with hypotension refractory to intravascular volume loading, associated with perfusion abnormalities that required the use of inotropes.

The definition of a multidrug-resistant (MDR) pathogen was used to describe a methicillin-resistant, an extended-spectrum $\beta$ lactamases-producing Gram-negative strain, or any bacterial isolate resistant to at least 3 classes of antimicrobial agents. 


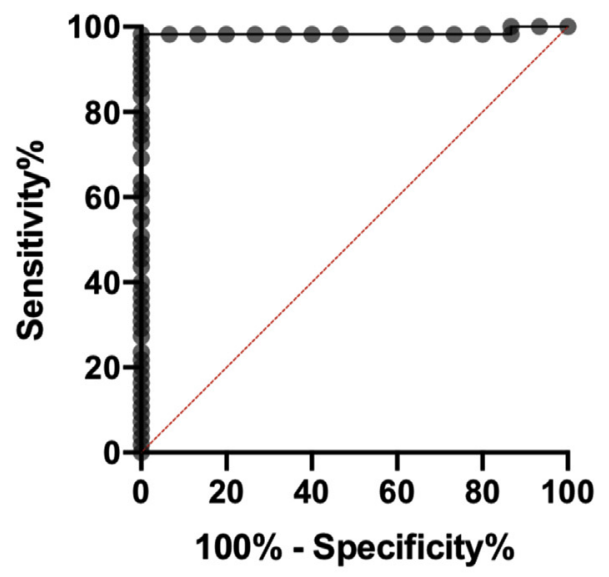

sCD14

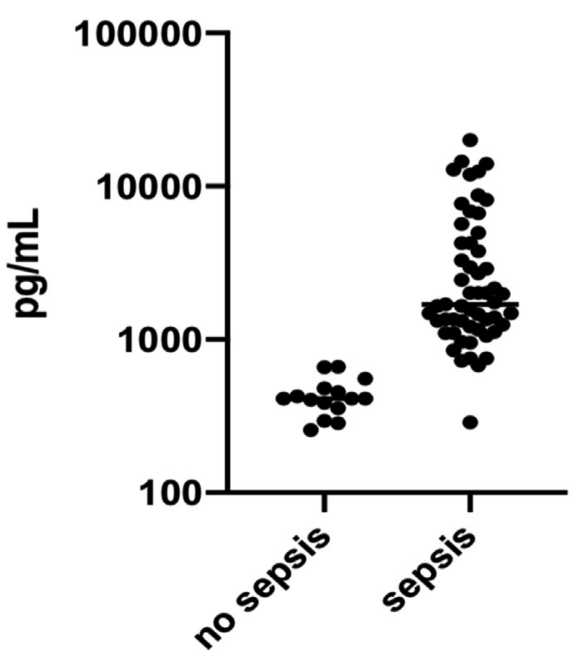

Fig 1. Receiver operator characteristic analysis for a correct cutoff value.

The definition of decompensated cirrhosis follows the consensus recommendations of the Asian Pacific Association for the Study of the Liver in March 2009.

\section{Statistical Analysis}

Categorical data were summarized as proportions and percentages; continuous data, as mean values and standard deviations, were reported. Statistical analysis was performed using GraphPad InStat software (GraphPad Software, San Diego, Calif, USA), version $6.0 \mathrm{~b}$. To determine differences between groups not normally distributed, medians were compared using the Mann-Whitney $U$ test. A $P$ value $<.05$ was considered significant. The results are depicted in boxplots.

We performed a Roc analysis in order to determine a cutoff value for the sepsis (Fig 1). The cutoff value was a sdC14 value greater than $669.5 \mathrm{pg} / \mathrm{mL}$ with a specificity of $98.1 \%$ and sensitivity of $99.1 \%$.

The area under the curve is $0.98 \%$, standard error of 0.01 , $P$ value of .001 , and a positive predictive value and negative predictive value of $96.08 \%$ and $99.5 \%$, respectively.

\section{RESULTS}

Seventy patients with a diagnosis of decompensated cirrhosis were evaluated at admission (Table 1). Forty-nine resulted positive to PATHFAST with a mean presepsin level of $1854 \pm 1744 \mathrm{pg} / \mathrm{mL}$. The mean MELD score was 26 \pm 1.6 , and 22 patients $(45 \%)$ resulted as asymptomatic at admission.

In these 49 patients, the origin of cirrhosis was alcohol abuse in $37 \%$ of cases, hepatitis C in $39 \%$, hepatitis B in $18 \%$, and primary biliary cirrhosis in $6 \%$.

The main reasons for hospital admission of 49 patients were as follows: refractory ascites in 14 patients $(28.5 \%)$, variceal bleeding in $11(22.5 \%)$, encephalopathy in $8(16 \%)$, suspected infection in $7(14 \%)$, and renal failure in $9(19 \%$; Table 2).

The patients affected by refractory ascites showed a mean value of presepsin of $1216 \pm 319.87 \mathrm{pg} / \mathrm{mL}$; by variceal bleeding $1036 \pm 425.38 \mathrm{pg} / \mathrm{mL}$; by encephalopathy $700 \pm$ $168.76 \mathrm{pg} / \mathrm{mL}$; by suspected infection $2282 \pm 536.06 \mathrm{pg} / \mathrm{mL}$, and by renal failure for a mean value of $1700 \pm 959.21 \mathrm{pg} /$ $\mathrm{mL}$ (Fig 2).

As reported in Fig 3, a significant decrease of sCD14 was observed at the different time points in response to the antibiotic therapy and an improvement of clinical status. Thirty-three $(67.5 \%)$ patients, highlighting a decrease of presepsin levels, were considered responders to EAT. Presepsin level values began to decrease at (T2) and fell below threshold level at (T3; Fig 4).

However, at (T2), 16 patients (32.5\%) who showed an increase of presepsin levels (Fig 4) were evaluated as no responders to EAT.

In 4 of these patients, after antibiogram results, a specific antibiotic therapy was applied, and more time was necessary to lower presepsin levels below threshold levels of 377 $\mathrm{pg} / \mathrm{mL}$.

In the other 12 patients, who were still waiting for the cultures results, a different empirical treatment was suggested with meropenem ( $2 \mathrm{~g} /$ day $)$ and vancomycin ( $2 \mathrm{~g} /$ day). As shown in Table 3, 5 of these 12 patients had an infection caused by an MDR bacteria and died during their hospital stay, showing an increase of presepsin levels at the different time points.

Microbiological findings confirmed the presence of bacterial infections within $84 \pm 4.8$ hours from enrollment in all 49 patients (Table 3 ). In 8 patients (12\%), with low values of CD14s $(<500 \mathrm{pg} / \mathrm{mL})$, we obtained a urine culture positive only. Eleven patients who were hospitalized for refractory ascites showed a positive ascetic fluid cell analysis. Gramnegative organisms, particularly Escherichia coli, were isolated more frequently $(62 \%)$ than Gram-positive ones (38\%) (Fig 5).

No significant correlation $(\mathrm{R}=0.402)$ was found between CD14s and a MELD score of 49 patients at admission, as reported in Fig 6.

The negative patients $(\mathrm{n}=21)$ to $\mathrm{sCD} 14$ showed either a negative urine or blood culture. No correlation was found 
Table 2. Demographic, Clinical, and Biochemical Characteristics of Patients Positive to Presepsin

\begin{tabular}{lc}
\hline Patients (No. 49) & \\
Age (years) & $51.4 \pm 4.9$ \\
Sex (male/female) & $36 / 13$ \\
sCD14 (pg/mL) & $1854 \pm 1744$ \\
MELD Score & $26 \pm 1.6$ \\
Serum bilirubin (mg/dL) & $12 \pm 2.9$ \\
Serum creatinine (mg/dL) & $1.7 \pm 1.5$ \\
Serum albumin (g/dL) & $2.2 \pm 0.6$ \\
Serum lactate (mmol/L) & $2.1 \pm 0.7$ \\
Arterial ammonia (mg/dL) & $178 \pm 51.5$ \\
PMN count (cells/mm $\left.{ }^{3}\right)$ & $10,560 \pm 3277$ \\
INR & $2.2 \pm 0.9$ \\
mAP (mm Hg) & $73 \pm 7.2$ \\
HR (b/min) & $97 \pm 2.8$ \\
Cause of Cirrhosis & \\
Alcohol & $18(37 \%)$ \\
HCV & $19(39 \%)$ \\
HBV & $9(18 \%)$ \\
PBC & $3(6 \%)$ \\
Precipitating Events & \\
Ascites & $14(28.5 \%)$ \\
Variceal bleeding & $11(22.5 \%)$ \\
Renal failure & $9(19 \%)$ \\
Suspected bacterial infection & $7(14 \%)$ \\
Encephalopathy & $8(16 \%)$ \\
\hline Categorical data were summarized as proportions & and \\
continuous data, as mean values and standard deviations, were reported. \\
Abbreviations: HBV, hepatitis B virus related; HCV, hepatitis C virus related; \\
HR, heart rate; INR, international normal ratio; mAP, mean arterial pressure; \\
MELD, Model for End-Stage Liver Disease; PBC, primary biliary cirrhosis; PMN, \\
polymorph-nuclear.
\end{tabular}

between presepsin values and kind of pathogens. At 30 days of follow-up, 43 patients (88\%) survived, and 6 died (12\%).

\section{DISCUSSIONS}

The present study on the use of presepsin as a biomarker for bacterial infections contains some limitations that merit considerations. First, it was a single-center study and did not compare sCD14 with other biomarkers or severity score systems. Second, the possible risk factors of bacterial infections have not been investigated.

Conversely, bacterial infections are frequent and represent a relevant issue in cirrhotic patients. Patients with cirrhosis are immunocompromised and as such are highly susceptible to dissemination of infections, which can lead to worsening of hepatic function and the development of severe disease complications; therefore, early diagnosis of infections remains the goal.

In the present study, we analyzed a new rapid measurement method for whole blood that uses a chemiluminescence enzyme immunoassay and a new biomarker for bacterial infection. The PATHFAST assay system demonstrated a sufficient analytical performance. The sensitivity of the PATHFAST assay was sufficient to detect the presepsin concentrations in cirrhotic patients within 15 minutes.

Presepsin could be considered a highly specific marker for the diagnosis of bacterial infections in comparison to other sepsis markers because of its mechanism of production by bacterial phagocytosis. In a multicenter prospective study on 207 patients, Endo et al [31] showed that the area under the

\section{$\mathrm{pg} / \mathrm{mL}$}

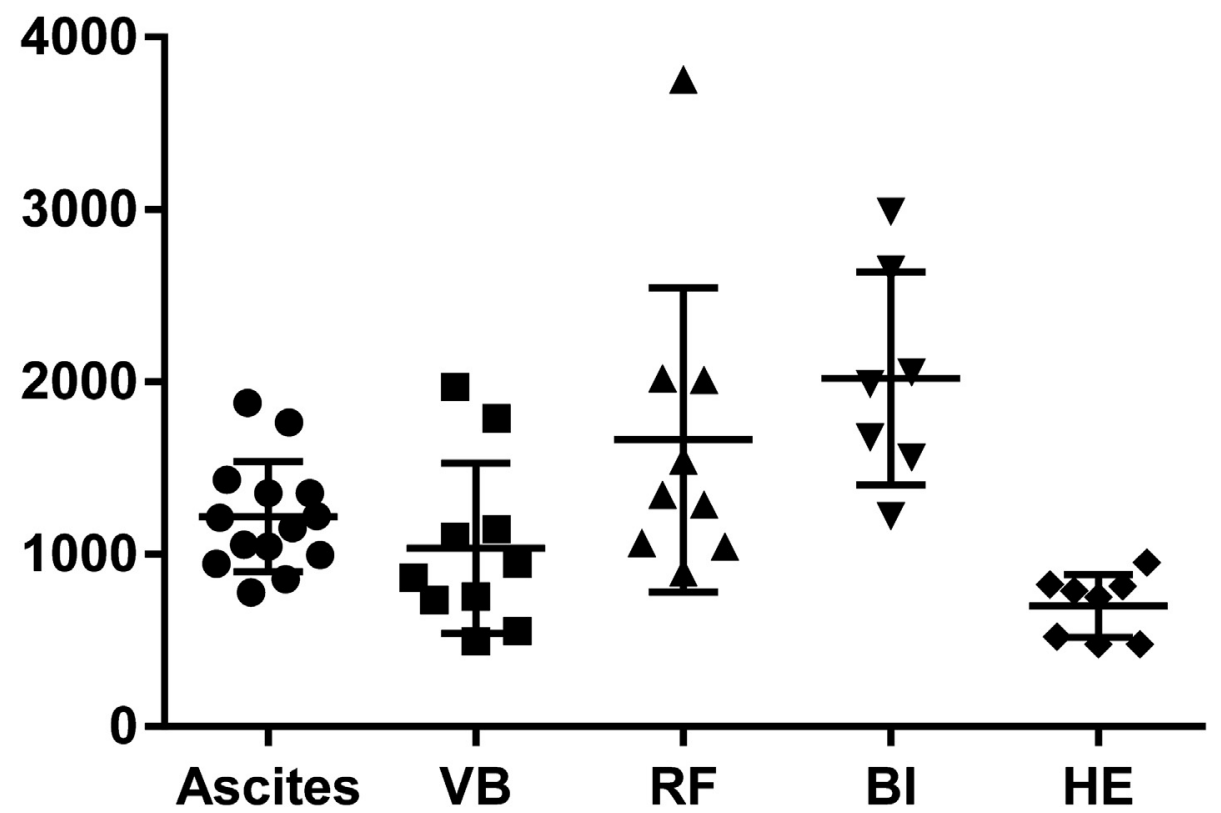

sCD14
Fig 2. Scatter plot of mean sCD14 levels evaluated at admission, divided following the precipitating events. BI, bacterial infections; $\mathrm{HE}$, hencephalopathy; RF, renal failure; VB, variceal bleeding. 


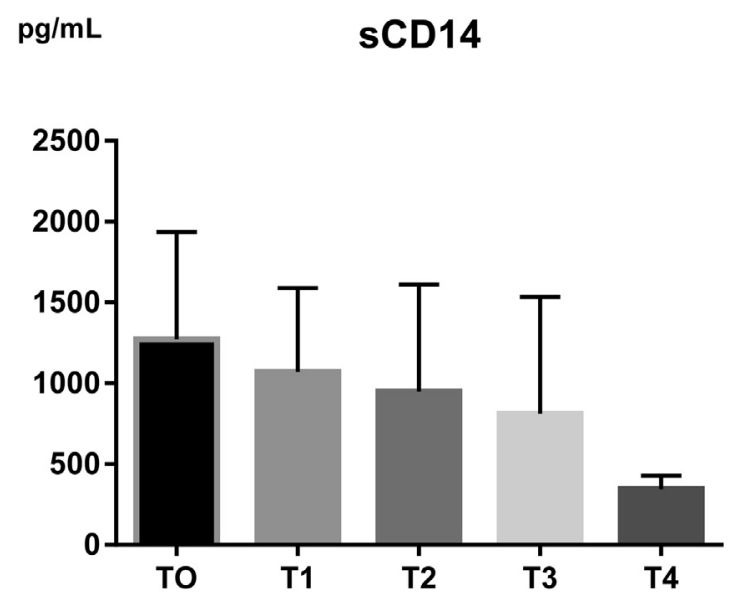

Fig 3. Scatter plot of mean sCD14 levels valuated in plasma samples (49 pts) at different time points. Admission T0; 48h T1; 96h T2; 144h T3; 15 days T4. Statistical analysis was performed with Mann-Whitney $\mathrm{U}$ test. $P$ value $<.05$ was considered statistically significant.

receiver operating characteristic curve was 0.908 for presepsin, 0.905 for PCT, and 0.825 for IL-6 in patients with bacterial infectious disease and those with nonbacterial infectious disease.

Presepsin is secreted from granulocytes by infectious stimuli with a sensitivity of $95.5 \%$ for Gram-positive and $88.8 \%$ for Gram-negative bacterial infections. In accordance to a study of Shozushima et al [36], no significant differences in presepsin levels between the Gram-positive and Gram-negative bacterial infection groups was observed. On the other hand, Gram-negative bacteria groups were more represented than gram positive bacteria. As reported in a paper of Gustot et al [6], the causative organisms of community-acquired infection are Gramnegative bacilli in about $60 \%$, Gram-positive cocci in about $30 \%$ to $35 \%$, and mixed in the last $5 \%$ to $10 \%$.

In addition, bacterial overgrowth and translocation from the gastrointestinal tract are important steps in the pathogenesis of spontaneous bacterial peritonitis (SBP) and

\section{Responder vs no Responder}

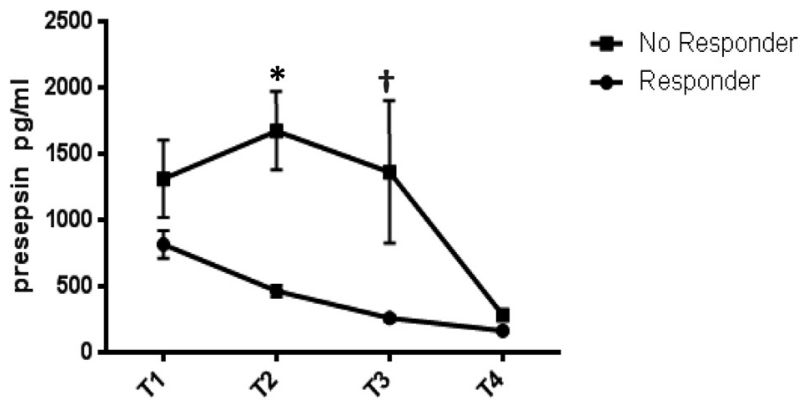

Fig 4. Scatter plot of mean SCD14 levels valuated in plasma samples of responders (38 pts) and no responders (11 pts) to empirical antibiotic therapy at different time points. ${ }^{*} P=.002$; ${ }^{\dagger} P=.03$; no significant differences at $\mathrm{T} 1$ and T4. T2: Empirical antibiotic therapy changed in 11 no responder patients; $48 \mathrm{~h}$ T1; 96h T2; 144h T3; 15 days T4. Statistical analysis was performed with Mann-Whitney $U$ test. $P$ value $<.05$ was considered statistically significant.

bacteremia. These processes increase levels of endotoxins and cytokines that induce the inflammatory response and can lead to septic shock, multiorgan dysfunction, and death.

Specifically, Escherichia coli, Klebsiella, and other Enterobacteriaceae most frequently cause infection in patients with cirrhosis [37] and have been found to be the most adept at translocating from the gut [38]. Escherichia coli, the pathogen more relived in this study $(37.5 \%)$, has been shown to translocate more efficiently, probably as a result of a greater ability to adhere to the intestinal mucosa.

An interesting aspect was the presence of $45 \%$ of patients without signs or symptoms of infection at admission. In these patients, the sCD14 evaluation was important to highlight the early phase of infection, starting with EAT. However, a more relevant emerging problem in cirrhotic patients is the increased prevalence of multidrug-resistant (MDR) bacteria.

Twelve patients resulted as no responders to EAT, thus 4 patients, hospitalized by alcohol-related cirrhosis with renal failure or suspected infection as precipitating events, were

Table 3. Mean CD14s VALUEs at Admission, Blood and Urine Culture Results, and Outcomes of 49 Positive Patients in Respect to Microbiological Findings

\begin{tabular}{|c|c|c|c|c|c|}
\hline Pathogens & Total & Mean sCD14 & $\begin{array}{l}\text { Blood Culture } \\
\text { Positive }\end{array}$ & $\begin{array}{l}\text { Urine Culture } \\
\text { Positive }\end{array}$ & Survival of Patients \\
\hline Escherichia coli & $19(38.7 \%)$ & $1620 \pm 885$ & $15(79 \%)$ & $4(21 \%)$ & $18(95 \%)$ \\
\hline Enterococcus & $8(16.3 \%)$ & $814 \pm 99$ & $8(100 \%)$ & - & $8(100 \%)$ \\
\hline Staphylococcus aureus & $6(12 \%)$ & $866 \pm 307$ & $4(66 \%)$ & $2(33 \%)$ & $6(100 \%)$ \\
\hline Pseudomonas aeruginosa & $5(10 \%)$ & $2655 \pm 765$ & $5(100 \%)$ & - & $4(80 \%)$ \\
\hline Klebsiella MDR & $4(8 \%)$ & $1100 \pm 333$ & $4(100 \%)$ & - & $1(25 \%)$ \\
\hline Klebsiella & $3(6 \%)$ & $1055 \pm 459$ & $2(66 \%)$ & $1(33 \%)$ & $3(100 \%)$ \\
\hline Proteus mirabilis & $2(4 \%)$ & $740 \pm 201$ & - & $2(100 \%)$ & $2(100 \%)$ \\
\hline Acinetobacter MDR & $1(2 \%)$ & 1635 & $1(100 \%)$ & - & 0 \\
\hline
\end{tabular}

Survival of patients evaluated at 30th day.

Abbreviation: MDR, multidrug resistance. 


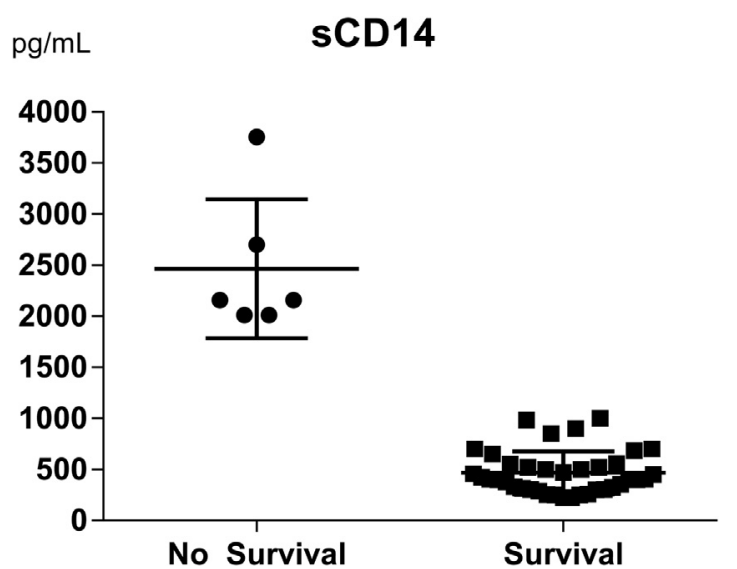

Fig 5. Scatter plots of mean sCD14 levels valuated in plasma samples of survived (43 pts) and not survived (6 pts) at T4.

affected by Klebsiella MDR. These 4 patients, who died from septic shock between the 15th and 24th day, showed presepsin values lower at admission than other surviving patients, highlighting no correlation between presepsin values and kind of pathogen.

SBP is the most common infection in cirrhotic patients with ascites and represents one of the most studied infections because of the severe prognosis and high rate of recurrence. In our cohort, the ascites represented a cause of hospitalization in 21/70 patients (30\%); 11 patients showed SPB.

Ten patients $(90 \%)$ with SPB resulted as responders to EAT with a decrease of presepsin levels corresponding to a decrease of ascitic neutrophil count to $<250 / \mathrm{mm}^{3}$ and sterile cultures of ascitic fluid to (T3).

In total, 38 were considered responders to EAT, showing presepsin level reduction and negative cultures at (T3).

In 8 responders with a diagnosis of SIRS, we highlighted positive urine cultures only. Shozushima et al [36] showed

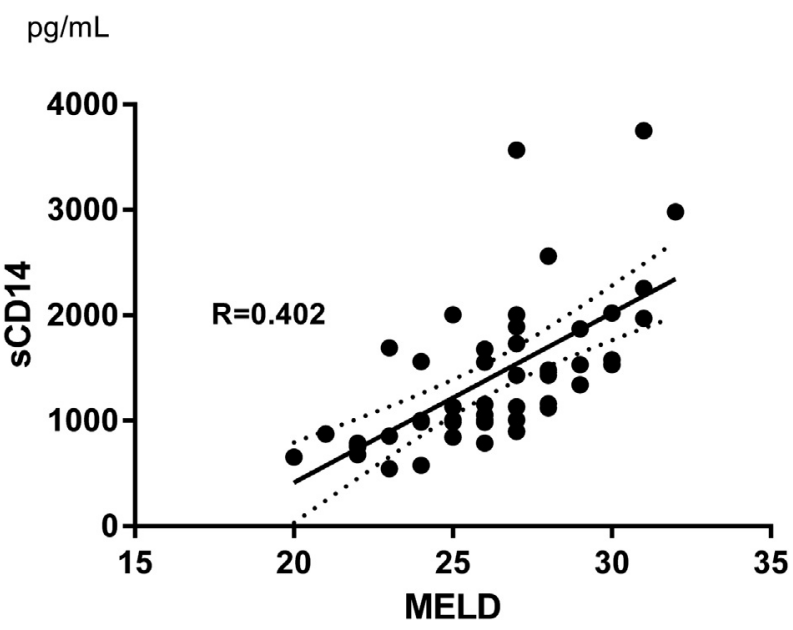

Fig 6. Scatter plot of linear regression of correlation between sCD14 levels and MELD score of 49 patients at admission. MELD, Model for End-Stage Liver Disease. that Cd14s levels were significantly lower in SIRS (343 \pm $130 \mathrm{pg} / \mathrm{mL}$ ) not complicated by infection than patients with sepsis, or severe sepsis, suggesting that presepsin increases specifically in infections.

Maybe, the cutoff of $377 \mathrm{pg} / \mathrm{mL}$, as indicated by manufacturers, is too low to underline the presence of systemic infection and start an empirical antibiotic therapy.

The antimicrobial treatment failure is relevant in cirrhotic patients but extremely difficult to estimate. A meta-analysis [39] of 5 studies performed in patients with gastrointestinal bleeding has shown that antibiotic prophylaxis significantly decreased both the incidence of severe infections (SBP or septicemia) and mortality.

On the other hand, given the inevitable risk of developing resistant organisms, the use of prophylactic antibiotics must be rigorously restricted. Causes include altered pharmacokinetics due to chronic liver failure and portal hypertension, which may alter absorption and distribution of orally administered drugs, expansion of the extracellular fluid compartment due to low serum albumin, and ascites that may increase the volume of distribution of hydrophilic antimicrobials, whereas reduced first-pass metabolism or total hepatic biotransformation may increase exposure to and decrease clearance of lipophilic antimicrobials [40-44].

Finally, at the 30th day of follow-up, $88 \%$ of patients with infection survived, while $12 \%$ died. As reported in 2 Italian studies, the in-hospital mortality in patients with cirrhosis was $16 \%$ to $19 \%$ among those with infections (presence of MDR bacteria was not reported) and $7 \%$ to $10 \%$ among those without, respectively $[14,18]$.

\section{CONCLUSIONS}

Bacterial infection and sepsis are highly detrimental in cirrhosis and are frequently caused by immune paralysis of patients and a resistance to pathogens.

The identification of an early specific biomarker is fundamental to start an antibiotic treatment with the intent to stop the sepsis cascade. The PATHFAST Assay System seemed to be an early indicator of bacterial infection, evaluating the sCD14 levels. It is fast (15 minutes) and can be used as a guide either to start antibiotic therapy in the absence of severe symptoms or to check the success of antibiotic therapy.

In contrast to blood cultures, presepsin measurement can be performed quickly and easily, not only in laboratories but also in wards and intensive care units. This retrospective study needed a bigger number of patients to confirm these results.

\section{REFERENCES}

[1] Navasa M, Rodés J. Bacterial infections in cirrhosis. Liver Int 2004;24. 277-80.

[2] Garcia-Tsao G. Current management of the complications of cirrhosis and portal hypertension: variceal haemorrhage, ascites, and spontaneous bacterial peritonitis. Gastroenterology 2001;120: $726-48$.

[3] Yang YY, Lin HC. Bacterial infections in patients with cirrhosis. J Chin Med Assoc 2005;68:447-51. 
[4] Vilstrup H. Cirrhosis and bacterial infections. Rom J Gastroenterol 2003;12:297-302.

[5] Fernandez J, Gustot T. Management of bacterial infections in cirrhosis. J Hepatol 2012:S1-12.

[6] Gustot T, Durand F, Lebrec D, et al. Severe sepsis in cirrhosis. Hepatology 2009;50:2022-33.

[7] Arvaniti V, D'Amcio G, Fede G, et al. Infections in patients with cirrhosis increase mortality four-fold and should be used in determining prognosis. Gastroenterology 2010;139:1246-56.

[8] Foreman MG, Mannino DM, Moss M. Cirrhosis as a risk factor for sepsis and death: analysis of the National Hospital Discharge Survey. Chest 2003;124:1016-20.

[9] Plessier A, Denninger MH, Consigny Y, et al. Coagulation disorders in patients with cirrhosis and severe sepsis. Liver Int 2003;23:440-8.

[10] Pleguezuelo M, Benitez JM, Jurado J, et al. Diagnosis and management of bacterial infections in decompensated cirrhosis. World J Hepatol 2013;5:16-25.

[11] Byl B, Roucloux I, Crusiaux A, et al. Tumor necrosis factor alpha and interleukin 6 plasma levels in infected cirrhotic patients. Gastroenterology 1993;104:1492-7.

[12] Deviere J, Content J, Denys C, et al. Excessive in vitro bacterial lipolysaccharide-induced production of monkines in cirrhosis. Hepatology 1990;11:628-34.

[13] Preda CM, Ghita R, Ghita C, et al. A retrospective study of bacterial infections in cirrhosis. Maedica (Buchar) 2011;6: 185-92.

[14] Borzio M, Salerno F, Piantoni L, et al. Bacterial infection in patients with advanced cirrhosis: a multicenter prospective study. Dig Liver Dis 2001;33:41-8.

[15] Cazzaniga M, Dionigi E, Gobbo G, et al. The systemic inflammatory response syndrome in cirrhotic patients: relationship with their in-hospital outcome. J Hepatol 2009;51:475-82.

[16] Wong F, Bernardi M, Balk R, et al. Sepsis in cirrhosis: report on the 7th meeting of the International Ascites Club. Gut 2005;54:718-25.

[17] Dellinger RP, Levy MM, Carlet JM, et al. Surviving sepsis campaign: international guidelines for management of severe sepsis and septic shock: 2008. Crit Care Med 2008;36:296-327.

[18] Fasolato S, Angeli P, Dallagnese L, et al. Renal failure and bacterial infections in patients with cirrhosis: epidemiology and clinical features. Hepatology 2007;45:223-9.

[19] Papp M, Vitalis Z, Altorjay I, et al. Acute phase proteins in the diagnosis and prediction of cirrhosis associated bacterial infections. Liver Int 2011;10. https://doi.org/10.1111/j.1478-3231.2011. 02689.

[20] Simon L, Gauvin F, Amre DK, et al. Serum procalcitonin and C-reactive protein levels as markers of bacterial infection: a systematic review and meta-analysis. Clin Infect Dis 2004;39: 206-17.

[21] Bota DP, Van Nuffelen M, Zakariah AN, et al. Serum levels of $\mathrm{C}$-reactive protein and procalcitonin in critically ill patients with cirrhosis of the liver. J Lab Clin Med 2005;146:347-51.

[22] Gonzalez-Quintela A, Alonso M, Campos J, et al. Determinants of Serum concentrations of lipopolysaccharide-binding protein (LBP) in the adult population: the role of obesity. PLoS One 2013;8. e54600.

[23] Bazil V, Strominger JL. Shedding as a mechanism of downmodulation of CD14 on stimulated human monocytes. J Immunol 1991;147:1567-74.
[24] Bas S, Gauthier BR, Spenato U, et al. CD14 is an acute phase protein. J Immunol 2004;172:4470-9.

[25] Tobias PS, Soldau K, Ulevitch RJ. Isolation of a lipopolysaccharide binding acute phase reactant from rabbit serum. J Exp Med 1986;164:777-93.

[26] Tobias PS, Ulevitch RJ. Lipopolysaccharide binding protein and CD14 in LPS dependent macrophage activation. Immunobiology 1993;187:227-32.

[27] Schumann RR, Leong SR, Flaggs GW, et al. Structure and function of lipopolysaccharide binding protein. Science 1990;249: $1429-31$.

[28] Schumann RR. Old and new findings on lipopolysaccharidebinding protein: a soluble pattern-recognition molecule. Biochem Soc Trans 2011:39:989-93.

[29] Triantafilou M, Triantafilou K. Lipopolysaccharide recognition: CD14, TLRs and the LPS-activation cluster. Trends Immunol 2002;23:301-4.

[30] Moshage H. Cytokines and the hepatic acute phase response. J Pathol 1997:181:257-66.

[31] Endo S, Suzuki Y, Takahashi G, et al. Usefulness of presepsin in the diagnosis of sepsis in a multicenter prospective study. J Infect Chemother 2012;18:891-7.

[32] Novelli G, Morabito V, Ferretti G, et al. Pathfast presepsin assay for early diagnosis of bacterial infections in surgical patients: preliminary study. Transplant Proc 2013;45:2750-3.

[33] Kamath PS, Wiesner RH, Malinchoc M, et al. A model to predict survival in patients with end-stage liver disease. Hepatology 2001;33:464-70.

[34] Salerno F, Gerbes A, Ginès P, et al. Diagnosis, prevention and treatment of hepatorenal syndrome in cirrhosis. Gut 2007;56: $1310-8$.

[35] Garcia-Tsao G, Lim JK. Members of Veterans Affairs Hepatitis C. Resource Center Program. Management and treatment of patients with cirrhosis and portal hypertension. Am J Gastroenterol 2009;104:1802-29.

[36] Shozushima T, Takahashi G, Matsumoto N, et al. Usefulness of presepsin (SCD14-ST) measurements as a marker for the diagnosis and severity of sepsis that satisfied diagnostic criteria of systemic inflammatory response syndrome. J Infect Chemother 2011;17:764-9.

[37] Wiest R, Garcia-Tsao G. Bacterial translocation (BT) in cirrhosis. Hepatology 2005;41:422-33.

[38] Gabay C, Kushner I. Acute-phase proteins and other systemic responses to inflammation. N Engl J Med 1999;340:448-54.

[39] Bernard B, Grange JD, Khac EN, et al. Antibiotic prophylaxis for the prevention of bacterial infections in cirrhotic patients with gastrointestinal bleeding: a meta-analysis. Hepatology 1999;29: 1655-61.

[40] Chavez-Tapia NC, Barrientos-Gutierrez T, Tellez-Avila FI, et al. Antibiotic prophylaxis for cirrhotic patients with upper gastrointestinal bleeding. CDSR 2010.

[41] EASL clinical practice guidelines on the management of ascites, spontaneous bacterial peritonitis, and hepatorenal syndrome in cirrhosis. J Hepatol 2010;53:397-417.

[42] Koulaouzidis A, Bhat S, Saeed AA. Spontaneous bacterial peritonitis. World J Gastroenterol 2009;15:1042-9.

[43] Sheer TA, Runyon BA. Spontaneous bacterial peritonitis. Dig Dis 2005;23:39-46.

[44] Delco F, Tchambaz L, Schlienger R, et al. Dose adjustment in patients with liver disease. Drug Safety 2005;28:529-45. 